\title{
A educação em saúde ambiental como estratégia no combate às arboviroses: experiência realizada na comunidade Quilombola Canto Fazenda Frade, município de Oeiras, Piauí, Brasil
}

\section{Environmental health education as a strategy in the fight against arboviroses: experience performed in the Quilombola community Canto Fazenda Frade, municipality of Oeiras, Piauí, Brazil}

DOI: $10.46919 / \operatorname{archv} 1 \mathrm{n} 5-005$

Recebimento dos originais: $10 / 07 / 2020$

Aceitação para publicação: 30/08/2020

\author{
Antonio Carlos dos Santos \\ Doutorando em Desenvolvimento e Meio Ambiente rede PRODEMA/UFPI \\ Instituição: Universidade Federal do Piauí, Teresina - PI \\ Endereço: Av. Universitária, 1310 (TROPEN) 64.049-550 Teresina - Piauí - Brasil \\ E-mail: baulive@hotmail.com \\ Ivanilza Moreira de Andrade \\ Doutorado em Botânica pela Universidade Estadual de Feira de Santana \\ Instituição: Universidade Federal Delta do Piauí (UFDPar), Parnaíba - PI \\ Endereço: Av. São Sebastião, 2819 (Reis Velloso) 64202020 Parnaíba, Piauí - Brasil \\ E-mail: ivanilzaandrade@hotmail.com
}

\section{RESUMO}

Com o presente trabalho objetiva-se descrever a vivência profissional na execução de ação sobre a prevenção e combate às arboviroses na comunidade Quilombola, Canto Fazenda Frade no município de Oeiras, estado do Piauí. Foi realizado estudo descritivo que consistiu em um relato de experiência de educação em saúde ambiental, resultado da parceria de dois projetos intitulados "Ofícina Promoção da Equidade em Saúde a População Negra" e "Laboratório Móvel do Ciclo Biológico do Aedes aegypti" executados pela Secretaria de Saúde do Piauí - SESAPI. A oficina realizada teve a participação de $28 \%$ da população quilombola e a capacitação de $100 \%$ dos professores e alunos da Escola Municipal Benedito Sá, município de Oeiras no combate ao mosquito do gênero Aedes e enfrentamento à microcefalia. A pesquisa contribuiu aos acadêmicos e profissionais de saúde aquisição de novos conhecimentos sobre a dengue, Febre Chikungunya e Zika vírus e a vivencia de novas experiências interculturalmente com uma comunidade tradicional quilombola. Desta forma, conclui-se que este estudo foi de grande relevância para a saúde da comunidade de estudo no sentido de promover através da prática de educação em saúde ambiental a prevenção, atitudes e mudança de comportamento na forma de enfrentamento e combate ao mosquito transmissor de arboviroses.

Palavra-chave: Educação em Saúde Ambiental, Arboviroses, Aedes aegypti, Quilombola.

\begin{abstract}
This work aims to describe the professional experience in carrying out action on the prevention and fight against arboviruses in the Quilombola community, Canto Fazenda Frade in the municipality of Oeiras, state of Piauí. A descriptive study was carried out, which consisted of an account of the experience of education in environmental health, the result of the partnership of two projects entitled "Workshop on the
\end{abstract}


Promotion of Equity in Health to the Black Population" and "Mobile Laboratory of the Biological Cycle of Aedes aegypti" carried out by the Secretariat of Health of Piauí - SESAPI. The workshop held had the participation of $28 \%$ of the quilombola population and the training of $100 \%$ of the teachers and students of the Municipal School Benedito Sá, municipality of Oeiras in combating the mosquito of the genus Aedes and fighting microcephaly. The research helped academics and health professionals to acquire new knowledge about dengue, Chikungunya fever and Zika virus and to experience new experiences interculturally with a traditional quilombola community. Thus, it is concluded that this study was of great relevance for the health of the study community in order to promote, through the practice of environmental health education, prevention, attitudes and behavior change in the way of confronting and fighting the mosquito that transmits arboviruses.

Palavra-chave: Environmental Health Education, Arboviruses, Aedes aegypti, Quilombola.

\section{INTRODUÇÃO}

A Dengue, doença (arbovirose) causada pelo mosquito Aedes aegypti, se apresenta como um dos agravos de maior relevância epidemiológica no cenário brasileiro devido à alta taxa de morbimortalidade que vem ocorrendo em grande parte dos municípios de forma endêmica e em alguns momentos de forma epidêmica (BRASIL, 2009). Dentre as arboviroses existentes, além da dengue, encontram-se a Zika vírus e a Febre Chikungunya. Menciona-se que estas doenças têm seu agente etiológico, o Dengue-vírus, Zikavírus e Chikungunya-vírus, respectivamente, transmitidos no Brasil, essencialmente, pelo mosquito Aedes aegypti (BRASIL, 2016).

Aedes aegypti é um mosquito endêmico da África, diurno, de coloração preta, com listras e manchas brancas, adaptado ao ambiente urbano colonizado em depósitos de armazenamento de água e pequenas coleções temporárias (CROVELLO; HACKER, 1972; TAVEIRA; FONTES et al., 2001).

A dengue, Zika vírus e Febre Chikungunya, são causadas por vírus transmitidos pela picada da fêmea do Aedes quando o mesmo se encontra infectado. É notório na atualidade, particularmente, na região Nordeste do Brasil, a presença significativa da ocorrência de casos de Zika vírus e os reflexos derivados desta doença, como a provável relação com a microcefalia e outras síndromes congênitas ainda em estudo (SOUZA et al., 2018).

Frente ao evento inusitado de alteração do padrão da ocorrência de registros de microcefalia em recém-nascidos no País, incluindo o Piauí, e considerando a microcefalia um agravo emergencial em saúde pública, é necessário que a população em geral e profissionais de saúde se mobilizem no combate a esse vetor (BRASIL, 2015).

Deste modo, com todas as possíveis manifestações de doenças causadas por este mosquito é necessária uma atualização constante para melhor entendimento dessas doenças e seu controle. Uma das alternativas é por meio de ações de capacitação e de educação em saúde ambiental com objetivo de minimizar os problemas decorrentes da infestação desse vetor (SANTOS et al., 2016). 
De acordo com Lemos e Guerra (2004), a Educação Ambiental é uma ferramenta que demonstra ser estratégia fundamental para o processo de mudança de percepção do ambiente e com consequência direta nas atitudes tomadas pela sociedade. Ideia também corroborada pelos estudos de Mi et al. (2020), Lebaz, Zarhbouch e Picard (2020) e Fischer e Kowarik (2020).

A educação em saúde, por sua vez, é compreendida como o processo de transformação que desenvolve a consciência crítica das pessoas a respeito de seus problemas de saúde e estimula a busca de soluções coletivas para resolvê-los (BÓGUS, 2004).

Segundo Freitas et al. (2011), o sistema escravagista deixou profundas marcas no país; feridas que ainda perduram em não cicatrizar. Neste contexto de exclusão, desigualdades e racismo institucionalizado, emergem as comunidades tradicionais remanescentes de quilombos, lutando por acesso a políticas inclusivas para suas populações. Os quilombolas, assim como os da Fazenda Canto do Frade em Oeiras - PI, reivindicam direito à saúde plena e integral à sua comunidade.

É grande a necessidade de compreensão por todas as profissões ligadas à área de saúde, da importância das atividades de educação em saúde ambiental para o combate ao Aedes aegypti, uma vez que a efetividade das ações irá contribuir para diminuição dos casos, das internações e óbitos ocasionados por essas arboviroses evitando prejuízos sociais e econômicos nas populações mais como, por exemplo, as comunidades quilombolas.

De acordo com o Ministério da Saúde, a política de inclusão da população quilombola inicia-se, efetivamente, no ano de 2004 com a Portaria n. ${ }^{\circ}$ 1.434, de 14/07/2004 que criou um incentivo para a ampliação de equipes de Estratégia da Saúde da Família - ESF para as comunidades quilombolas (PARE; OLIVEIRA; VELOSO, 2007).

A Política Nacional de Desenvolvimento Sustentável dos Povos e Comunidades Tradicionais, em seu decreto $\mathrm{N}^{\circ}$. 6040, de 7 de fevereiro de 2007, define comunidades tradicionais como:

- grupos culturalmente diferenciados e que se reconhecem como tais, que possuem formas próprias de organização social, religiosa, ancestral e econômica, utilizando conhecimentos, inovações e práticas gerados e transmitidos pela tradição.

O uso de estratégias de informação como também de comunicação e educação, junto aos diferentes atores sociais envolvidos no processo, é fundamental para a implementação de ações coordenadas e compartilhadas de prevenção e controle das arboviroses e outros agravos (CHIARAVALLOTI NETO; MORAES; FERNANDES, 1998; DIAS, 1998; AUGUSTO; CARNEIRO; MARTINS, 2005; COELHO, 2008).

Diante da problemática da transmissão das arboviroses em nosso país, inclusive nos municípios do Piauí, onde se encontram comunidades remanescentes quilombolas e da dificuldade do acesso das 
mesmas aos bens e serviços públicos principalmente de saúde devido ao um processo histórico, objetivouse com o presente trabalho descrever a vivência em projeto de execução profissional sobre a prevenção e combate as arboviroses (Dengue, Chikungunya e Zika Vírus) na Comunidade Quilombola Canto Fazenda Frade em Oeiras, estado do Piauí.

\section{MÉTODO}

O estudo realizado foi descritivo, consistindo em um relato de experiência de educação em saúde ambiental, resultado da parceria de dois projetos intitulados "Oficina Promoção da Equidade em Saúde da População Negra" e "Laboratório Móvel do Ciclo Biológico do Mosquito da Dengue" da SESAPI. O primeiro projeto compreende todas as Comunidades Quilombolas no Piauí e o outro, além dos Quilombos, os 224 municípios que compõe o estado. Portanto, são expostos aspectos vivenciados por profissionais de saúde pertencentes às áreas de Vigilância em Saúde Ambiental e Promoção da Equidade em Saúde da Secretaria Estadual de Saúde do Piauí órgão financiador e executor dessas ações. A metodologia utilizada é semelhante a utilizada nos trabalhos Sales (2008), Santos et al. (2016) e Passos et al. (2017).

\section{3 ÁREA DE ESTUDO}

A comunidade remanescente quilombola Canto Fazenda Frade, fica localizada na zona rural a 25 quilômetros da sede do município de Oeiras, em uma área a leste que faz divisa com o município de São João da Varjota, com aproximadamente 150 famílias residentes e uma população estimada de 750 pessoas (Figura 01).

Figura 01 - Localização Comunidade Quilombola Canto Fazenda Frade

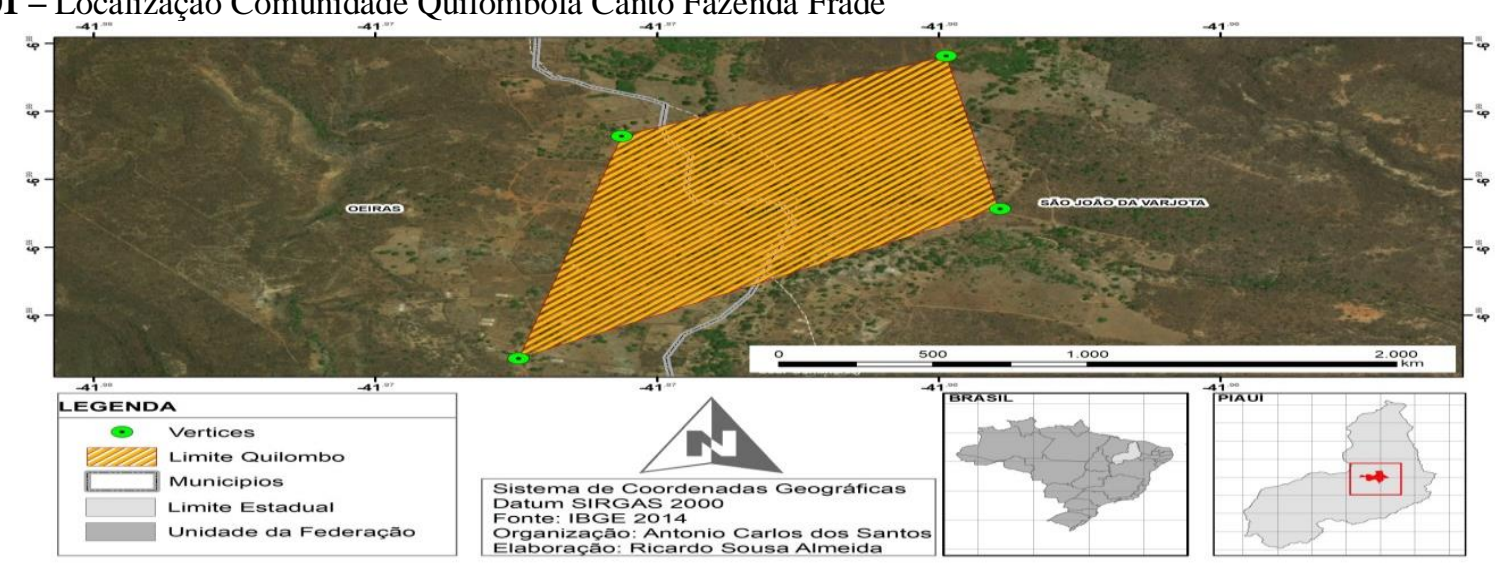

Fonte: IBGE (2014) 
O município de Oeiras, estado do Piauí, está localizado na microrregião de Picos, compreendendo uma área irregular de $2.737 \mathrm{~km}^{2}$. Tem como limites ao norte os municípios de Barra D’Alcântara, Tanque do Piauí, Novo Oriente do Piauí e Santa Rosa do Piauí, ao sul São Francisco do Piauí, Colônia do Piauí e Wall Ferraz, a oeste, Santa Rosa do Piauí, Nazaré do Piauí, São Francisco do Piauí e Cajazeiras do Piauí e, a leste, Inhuma, Ipiranga do Piauí, São João da Varjota e Santa Cruz do Piauí. A sede municipal tem as coordenadas geográficas de $07^{\circ} 01^{\prime} 31^{\prime \prime}$ de latitude sul e $42^{\circ} 07^{\prime} 52^{\prime \prime}$ de longitude oeste de Greenwich e dista cerca de $313 \mathrm{~km}$ de Teresina (CPRM/BRASIL, 2004).

\section{PLANO AMOSTRAL}

A pesquisa constou de duas etapas para o levantamento dos dados do estudo, durante o período de 27.11 a 01.12.2017. No primeiro momento realizou-se uma coleta de dados (casos de arboviroses e os endereços) utilizando o Sistema de Informação de Agravos de Notificação - SINAN da Secretaria de Estado da Saúde do Piauí - SESAPI. Buscou-se informações na Secretaria Municipal de Educação de Oeiras sobre a quantidade de alunos matriculados em 2017 na escola da comunidade como também a quantidade de professores. Informações populacionais e territoriais consultou-se o relatório do Projeto de cadastro de fontes de abastecimento por água subterrânea Piauí/Diagnóstico do município de Oeiras realizado pelo Serviço Geológico do Brasil - CPRM/BRASIL (2004). No segundo momento, identificouse os locais para realização das atividades previstas na oficina e montagem do Laboratório Móvel do Ciclo Biológico do Mosquito Aedes aeypti (vetor principal das arboviroses). Foi selecionada a Igreja Católica da Comunidade para realização das reuniões e Escola Municipal Benedito Sá para as palestras. Foram utilizados materiais educativos (revistas e folders), equipamentos como microscópio estereoscópico, gaiolas, cubas e tubos de vidro com amostras de mosquitos do gênero Aedes vivos e mortos, bonecos réplicas do mosquito Aedes aegypti (fêmea e macho), armadilhas do tipo CDC Luminosa para captura dos mosquitos, banners, máquina fotográfica e aparelho de Sistema de Posicionamento Global (GPS) para georreferenciamento. Este foi utilizado para elaboração do mapa da área de estudo.

\section{COLETA E TRATAMENTO DOS DADOS}

Como instrumento de coleta de dados foram utilizados questionários de diagnóstico socioambiental em saúde da Coordenação de Equidade em Saúde da SESAPI, com perguntas específicas sobre os problemas de saúde para as lideranças da comunidade durante a oficina e o uso da frequência tanto para os participantes da oficina como para registro dos visitantes em geral (alunos, pais, professores e comunidade) ao laboratório móvel do mosquito da dengue instalado no pátio da escola. Para avaliar a participação social dos alunos da escola, pais, professores e comunidade em geral das palestras e visitação 
ao laboratório móvel da dengue utilizou-se critérios de avaliação de edital de chamamento para elaboração de projeto de educação em saúde da Fundação Nacional de Saúde (2017) as quais as fórmulas seguem abaixo:

Avaliação do Projeto - Indicadores

$$
\begin{gathered}
\% \text { Participação nas oficinas }-\%=\frac{n^{2} \text { participantes }}{n^{2} \text { convidados }} \times 100 \\
\% \text { Professores e alunos capacitados }-\%=\frac{n^{8} \text { deprof essoresealunoscapacitados }}{n^{8} \text { deprof essoresealunosexistentes }} \times 100
\end{gathered}
$$

Os dados obtidos e analisados foram comparados com a literatura principalmente com os trabalhos de Pare; Oliveira; Velloso (2007), Santos et al. (2016) e Passos et al. (2017), entre outros. Segunda a FUNASA (BRASIL, 2017), a utilização dessa metodologia descrita deve favorecer a interação entre professores, alunos e comunidade em geral na perspectiva do fortalecimento da promoção da saúde.

Seguindo orientações da Política Nacional de Saúde Integral da População Negra do Ministério da Saúde, a Secretaria Estadual de Saúde - SESAPI, através da Coordenação de Equidade em Saúde, realizou em parceria com Conselho Estadual de Saúde do Piauí - CESPI e Secretaria Municipal de Educação de Oeiras - SEMED Oficina Promoção da Equidade em Saúde na Comunidade Quilombola Canto Fazenda do Frade no período de 27.11 a 01.12.2017.

Segundo SINTSPREVS-PI (2018), o presente evento foi organizado pela SESAPI em conjunto com o CESPI, Secretaria Municipal de Saúde e de Educação de Oeiras no qual na oficina além das palestras sobre temáticas diversas de Saúde contou com reuniões com lideranças do Quilombo na Igreja Católica da Comunidade como também com apresentações artísticas de alunos da Escola Municipal Benedito Sá.

A Política Nacional de Saúde Integral da População Negra tem o objetivo de garantir a equidade na atenção à saúde para esse segmento populacional. Tal medida possui um caráter compensatório em virtude das discriminações raciais existentes ao longo da história do Brasil (BRASIL, 2009; CHEHUEN NETO ET AL., 2014).

Os pontos marcados (Coordenadas Geográficas) com GPS foram plotados na base cartográfica digital do município de Oeiras, através de um Sistema de Informação Geográfica (SIG) no laboratório de geoprocessamento (Geoambiente) do Departamento de Geografia da UFPI. Os programas utilizados foram: Arc Gis 10.2, GPS Trackmaker 135, a imagem de satélite Landsat 5, do Global Land Survey, no sistema de projeção SIRGAS 2000 e imagem do Google Earth. O geoprocessamento pode ser definido 
como conjunto de técnicas de coleta, exibição e tratamento de informações espacializadas e o uso de sistemas que as utilizam (NEVES; KATZ, 2001).

\section{RESULTADOS E DISCUSSÃO}

A oficina foi realizada com intuito principal de levantar as demandas de saúde da comunidade e levar orientações do ciclo biológico do Aedes aegypti através do Laboratório Móvel do Mosquito da Dengue foram envolvidos 11 profissionais da SESAPI como técnicos em laboratório, agentes de saúde, atendentes etc; Dois Conselheiros Estadual de Saúde e uma estudante do Curso de Licenciatura plena em Pedagogia da Universidade Estadual do Piauí - UESPI.

No primeiro dia (27.11.2017) na chegada da equipe à comunidade houve uma reunião com a população residente para explicação dos trabalhos. A partir do dia seguinte (28.11.2020) pela manhã tivemos uma reunião com as lideranças na igreja católica da comunidade e paralelamente iniciamos a montagem do Laboratório Móvel do Mosquito da dengue no pátio da escola. À tarde a pedido dos líderes da comunidade realizou-se busca de endereços para investigação de pessoas com uma doença ainda desconhecida e para georreferenciamento de pontos para elaboração do mapa de localização da comunidade.

A comunidade Canto Fazenda Frade possui somente uma escola gerida pelo município de Oeiras com 19 alunos na educação infantil e 78 no ensino fundamental menor ( $1^{\circ}$ ao $5^{\circ}$ ano) somando um total geral 97 estudantes matriculados no ano de 2017 conforme quadro abaixo, nove professores e um diretor.

\begin{tabular}{|c|c|c|c|c|c|c|}
\hline \multirow[t]{2}{*}{ NOME DA ESCOLA } & \multicolumn{5}{|c|}{ EDUCAÇÃO INFANTIL } & \multirow[t]{2}{*}{ TOTAL } \\
\hline & \multicolumn{2}{|c|}{$\begin{array}{l}\text { MATERNAL } \\
\text { II } \\
\end{array}$} & PRÉ - I & \multicolumn{2}{|c|}{ PRÉ - II } & \\
\hline \multirow{4}{*}{ ESC. MUN. BENEDITO SÁ } & & & 08 & & & 19 \\
\hline & \multicolumn{5}{|c|}{ ENSINO FUNDAMENTAL } & \multirow[t]{2}{*}{ TOTAL } \\
\hline & $\begin{array}{c}1^{\circ} \\
\text { ANO } \\
\end{array}$ & $2^{\circ}$ ANO & $3^{\circ}$ ANO & $\begin{array}{r}4^{0} \\
\text { ANO } \\
\end{array}$ & $\begin{array}{r}5^{\circ} \\
\text { ANO } \\
\end{array}$ & \\
\hline & 09 & 16 & 19 & 25 & 09 & 78 \\
\hline & \multicolumn{5}{|c|}{ TOTAL GERAL } & 97 \\
\hline
\end{tabular}

Fonte: SEMED (2018)

Conforme informações da Secretaria Municipal de Educação de Oeiras, devido à pequena quantidade de alunos a Escola Municipal Benedito Sá da Comunidade Canto Fazenda Frade o seu funcionamento com estudantes em sala de aula é somente pela manhã. Durante o turno da tarde a escola funciona com atividades de reforço e educação física para os alunos e de planejamento de aulas dos professores. As 
crianças quando passam do $5^{\circ}$ ano (última série que a escola oferta) como também os jovens que irão cursar o ensino médio têm que ir para uma outra escola de uma comunidade próxima ou na sede do município para estudarem. A SEMED de Oeiras cumpre seu papel de estado para oportunizar as crianças e adolescentes do município, independente de raça e cultura, o direito de estudar assim como está previsto em nossa constituição e de outros países da América Latina como descrito por Acosta (2016).

No dia 29.11.2017 pela manhã realizou-se palestras individuais sobre arboviroses (dengue, Febre Chikunnya e Zica Vírus) nas turmas de Maternal II, Pré - I e II onde teve a participação de 100\% dos alunos e professores. Ao termino de cada palestra foram distribuídas revistas educativas sobre arboviroses (Figura 02) para cada aluno da turma, os quais foram organizados em fila (Figura 03) pelo professor para visitar o Laboratório do Ciclo Biológico do mosquito da dengue.

Figura 02: Foto - Alunos visualizando as revistas, cartazes e folders recebidas sobre as arboviroses.

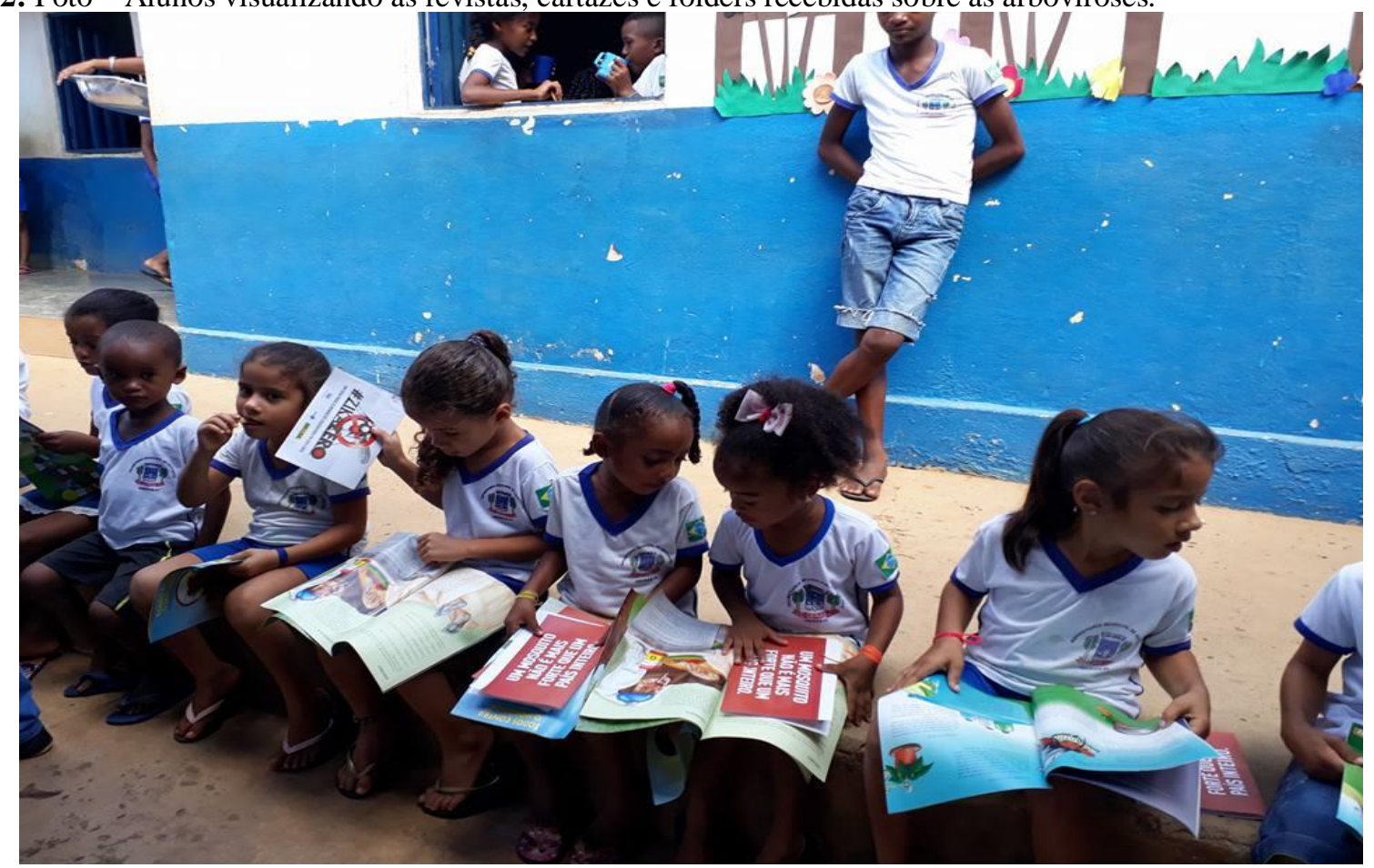

Fonte: Maura Carmélia (Técnica SESAPI) 


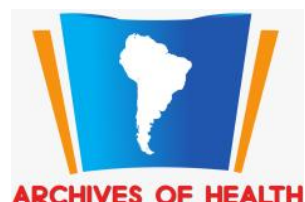

Figura 03: Foto - Fila de alunos para visitação do Laboratório móvel do mosquito da dengue.



Fonte: Maura Carmélia (Técnica SESAPI)

Durante a visita ao laboratório, o primeiro aparelho que as crianças ou visitantes tiveram contato foi o estereoscópico (lupa) (Figura 4), onde o técnico de entomologia orienta como deve-se utilizar o equipamento para uma visualização melhor dos detalhes do exemplar morto do mosquito Aedes (aegypti ou albopictus). Em seguida, o aluno visitante pode observar duas vasilhas com água, sendo uma com amostra de larvas vivas do Aedes aegypti, em vários estágios diferentes, e a outra na forma de pupa (estágio final da fase aquática antes de chegar na fase adulta).

Figura 04: Foto - Visualização dos mosquitos no aparelho estereoscópico (lupa) do Laboratório móvel do mosquito da dengue.

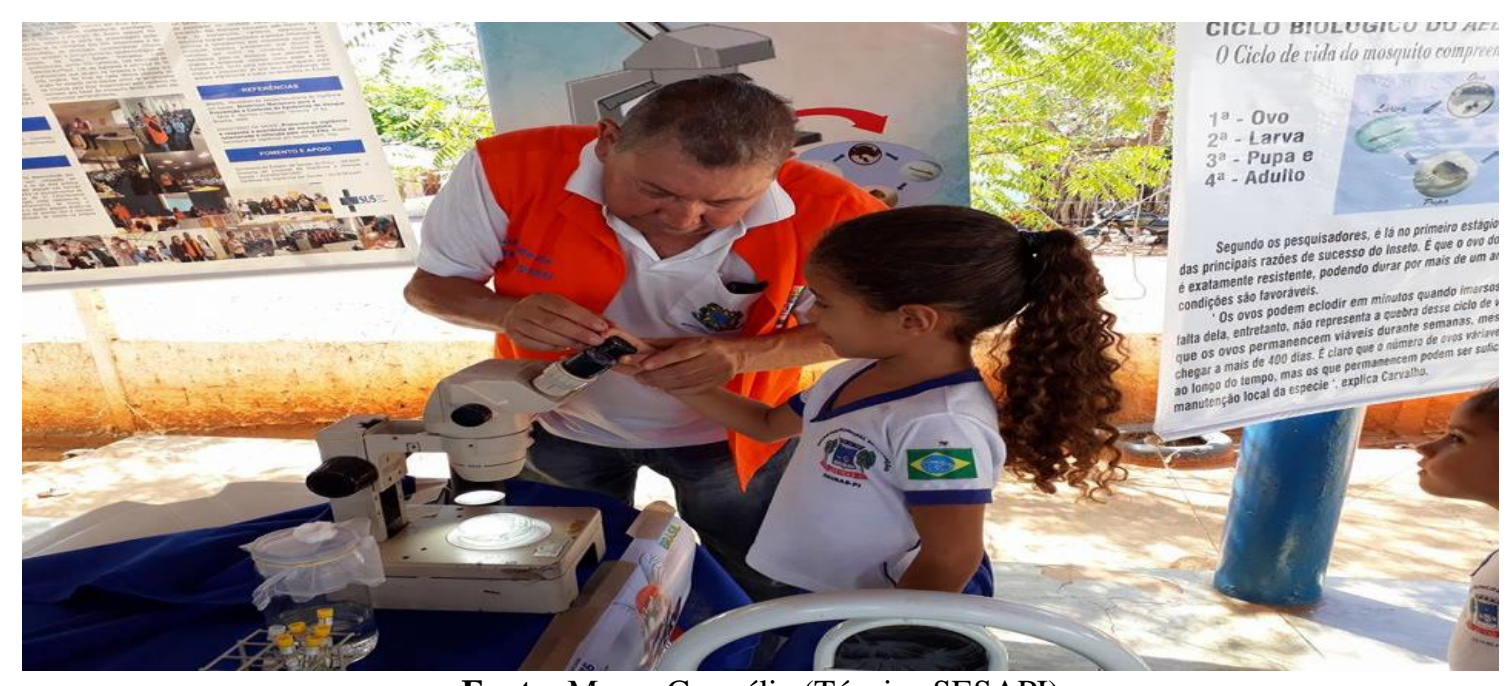

Fonte: Maura Carmélia (Técnica SESAPI) 


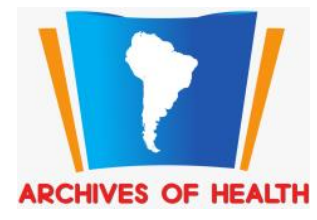

Na sequência da visita ao laboratório os alunos observaram, através de uma gaiola, amostras de mosquitos vivos, não infectados, criados no laboratório de entomologia da IV Coordenação Regional de Saúde de Teresina, órgão também ligado à SESAPI. Continuando a visitação as crianças tiveram contato com as mãos a duas réplicas gigantes do Aedes aegypti (macho e a fêmea), tubitos de vidro (com amostras de ovos, larvas e pupas mortas conservadas no álcool 70\%) e contatos com armadilhas de captura de mosquito do tipo CDC - Luminosa e com canhões aspiradores. Finalizando a visita com todas informações recebidas pelos técnicos da SESAPI integrantes da Equipe do Laboratório móvel do ciclo biológico do Aedes aegypti os alunos assinaram a frequência de visita ao laboratório (Figura 05) visitantes recebem folders, cartaz, revistas, panfleto, hipoclorito para levarem para suas residências.

Figura 05: Foto - Assinatura de frequência da visitação ao Laboratório móvel do mosquito da dengue.

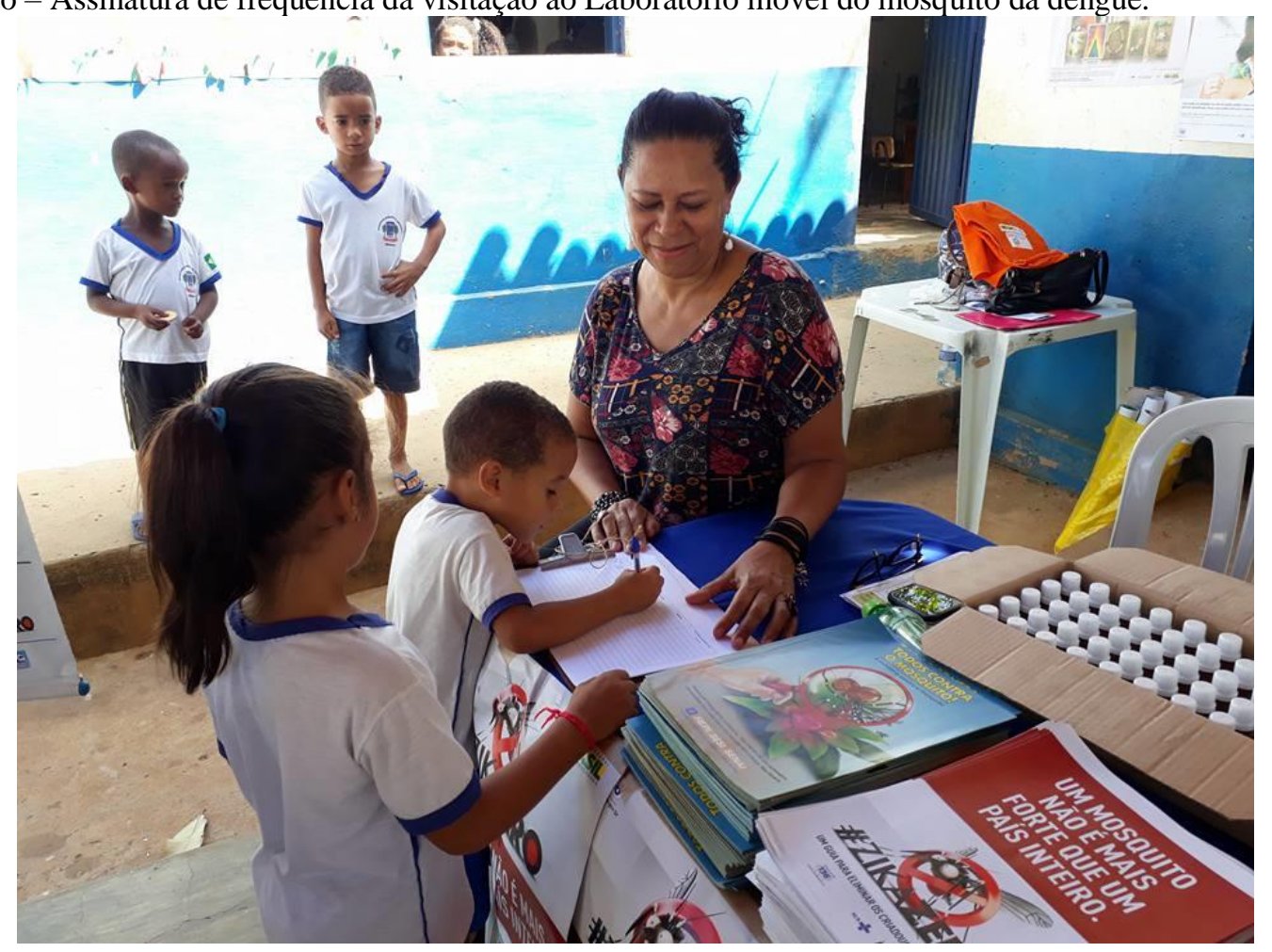

Fonte: Maura Carmélia (Técnica SESAPI)

Na manhã do dia 29.11.2017, com a mesma metodologia do dia anterior, deu-se continuidade à realização das palestras sobre arboviroses só que foi nas turmas de $1^{\circ}$ (primeiro) ao $5^{\circ}$ ano da Escola Municipal Benedito Sá. Segundo dados da SEMED/Oeiras, conforme quadro 01, quantidade de alunos de $1^{\circ}$ ao $5^{\circ}$ ano é de 78 estudantes e de acordo com nossa frequência tivemos a participação de $100 \%$ nas palestras desse total. Como o laboratório foi montado no pátio da escola, no horário de encerramento do turno, houve visita também dos pais que vinham buscar os filhos e dos transeuntes que passavam na rua, até por curiosidade da movimentação e devido relato das crianças do que viram. 
O encerramento da Oficina de promoção a equidade em saúde e consequentemente da exposição do Laboratório Móvel da dengue, na manhã do dia 30.11.2017, contou com apresentação cultural de capoeira e de dança pelos alunos da escola e também além dos pais de alunos, com a presença das lideranças da comunidade e de representantes da SEMED de Oeiras.

Ao todo pela as análises realizadas nas frequências de visitação (alunos e comunidade) do Laboratório móvel da dengue e da reunião com as lideranças da comunidade em relação ao número de convidados (a população estimada 750 pessoas) segundo a fórmula de Avaliação do Projeto - Indicadores Brasil (FUNASA, 2017):

$$
\begin{gathered}
\% \text { Participação nas oficinas }-\%=\frac{208}{750} \times 100=27,73 \% \\
\% \text { Professores e alunos capacitados }-\%=\frac{107}{107} \times 100=100 \%
\end{gathered}
$$

Houve a participação de cerca de $28 \%$ da população da Comunidade Canto Fazenda do Frade na Oficina de Promoção da Equidade em Saúde e 100\% dos professores e alunos foram capacitados através do Projeto do Laboratório Móvel do Ciclo Biológico do Aedes aegypti no combate ao mosquito do gênero Aedes e enfrentamento à microcefalia dentro da Escola Municipal Benedito Sá e consequentemente na Comunidade. Através dos resultados pode-se observar que a população, principalmente alunos e os professores, se mobilizou socialmente a participarem das atividades de capacitação de educação em saúde ambiental oferecidas pela SESAPI/CESPI e SEMED/Oeiras - PI análises corroboradas com as pesquisas de Santos et. al. (2016) e SINTSPREVS/PI (2018).

As atividades como estas que foram desenvolvidas na Comunidade Quilombola Canto Fazenda Frade, que segundo Ponciano; Santos; Oliveira (2014) são consideradas de Educação e Mobilização Social por se tratar de uma ação educativa que visa à emancipação dos sujeitos e permitindo a inclusão social dos mesmos, não só de forma imediata, mais na formação de uma consciência crítica de um novo ser social na condição de cidadania.

Segundo Cavalcante (2011), a Educação Ambiental é constituída por diversos valores sociais, informações, capacidades, costumes e confiabilidades regressadas em prol da conservação ambiental e da sustentabilidade. Os alunos da Escola Benedito Sá após serem capacitados e depois trazerem seus pais para visitarem o laboratório demonstrou que a aplicação da ferramenta da Educação em Saúde Ambiental no ambiente escolar foi de extrema relevância no processo de sensibilização e conscientização delas e de seus responsáveis. O estudo de Pereira (2014) revelou a importância da aplicabilidade da Educação Ambiental para alunos e seus pais de duas escolas do município de Araranguá, Santa Catarina. 


\section{CONCLUSÃO}

Conclui-se acerca da discussão da vivência em projeto de execução profissional sobre a prevenção e combate às arboviroses como dengue, Chikungunya e Zica Vírus na Comunidade Quilombola Canto Fazenda Frade em Oeiras - PI que:

I - A Oficina de promoção equidade em saúde em parceria com projeto Laboratório móvel do Aedes aegypti realizada com intuito de levantar as demandas de saúde da comunidade e levar orientações do ciclo biológico do Aedes aegypti atendeu os seus objetivos reunindo-se com as lideranças para discutir as suas demandas, envolveu quase $29 \%$ da população em suas atividades e capacitou $100 \%$ dos alunos e professores da Escola Benedito Sá no combate as arboviroses e enfrentamento a microcefalia;

II - Foram sensibilizados quanto à importância de conservar os seus quintais limpos, sem presença nada sem utilidade que acumule água e se tiver serventia que seja coberto com a tampa. Realizou-se esclarecimento de dúvidas sobre entre a fêmea e o macho do Aedes aegypti, da atração da fêmea pelo sangue humano e do hábito de picar durante o dia exemplificando através das réplicas do boneco gigante;

III - Observou-se que o projeto trouxe benefícios acadêmicos para o 01 aluno de graduação em pedagogia, e para profissional da SESAPI com mestrado em geografia da saúde. Para os acadêmicos e profissionais envolvidos, a experiência se mostrou importante, pois proporcionou aquisição de novos conhecimentos sobre as arboviroses e de vivência intercultural com uma comunidade tradicional quilombola;

IV - As atividades permitiram uma abordagem dinâmica sobre o assunto, sendo possível entender que existem lacunas na prevenção e combate dessas arboviroses entre os moradores da comunidade, percebido pela apresentação de inúmeras dúvidas e depoimentos dos visitantes ao laboratório móvel do mosquito da dengue;

Desta forma, conclui-se que este estudo foi de grande relevância para a saúde da Comunidade Quilombola Canto Fazenda Frade no sentido de promover através da prática de Educação em saúde ambiental a prevenção em despertar atitudes e mudança de comportamento na forma de enfrentamento e combate ao mosquito transmissor das arboviroses. E sugere-se que a metodologia seja utilizada com outras comunidades, municípios e regiões do País. 


\section{REFERÊNCIAS}

ACOSTA, Alberto. O Bem Viver: uma oportunidade para imaginar outros mundos. São Paulo: Autonomia Literária; Ed. Elefante, 2016.

Augusto, L. G. S.; CARnEIRO, R. M.; MARTINS, P. H. (Eds.) Abordagem Ecossistêmica em Saúde: ensaios para o controle da dengue. Recife: Editora

Universitária da UFPE, 2005.

BRASIL. Ministério da Saúde. Dengue diagnóstico e manejo clínico adulto e criança. Brasília: Secretaria de Vigilância em Saúde, 2016. 58p.

BRASIL. Ministério de Minas e Energia/CPRM. Projeto Cadastro de Fontes de Abastecimento por Água Subterrânea/Diagnóstico do Município de Oeiras - PI. $1^{a}$ edição. Fortaleza - CE, 2004, 19p.

BRASIL. Fundação Nacional de Saúde - Funasa. EDITAL DE CHAMAMENTO PÚBLICO N. 01/2017/DESAM/FUNASA/MS.

Disponível em: file:///C:/Users/Antinio\%20Carlos/Documents/Edital\%20\%20Funasa\%20Dengue\%20Chikungunya\%20Z ica\%202017.pdf Acesso em: 17.08.2020.

BRASIL. Presidência da República. Gabinete da Casa Civil. Subchefia para Assuntos Jurídicos. DECRETO No 6.040, DE 7 DE FEVEREIRO DE 2007. Disponível em: http://www.planalto.gov.br/ccivil_03/ato2007-2010/2007/decreto/d6040.htm . Acesso em: 17.08.2020.

BRASIL. Ministério da Saúde/Secretaria de Vigilância em Saúde. Diretrizes Nacionais para a Prevenção e Controle de Epidemias de Dengue - Série A. Normas e Manuais Técnicos. $1^{\circ}$ Ed. Brasília, 2009.

BRASIL. Ministério da Saúde. Política Nacional de Saúde Integral da População Negra (PNSIPN). Portaria GM/MS no. 992, de 13 de maio de 2009. Brasília - DF. Disponível em: https://bvsms.saude.gov.br/bvs/publicacoes/politica_nacional_saude_populacao_negra_3d.pdf . Acesso em: 26.08.2020.

BRASIL. Ministério da Saúde. Protocolo de vigilância e resposta à ocorrência de microcefalia relacionada à infecção pelo vírus Zika. Brasília: Secretaria de Vigilância em Saúde, 2015. 55p.

BÓGUS, C. M. (2004). A promoção da saúde como referencial para a formulação e desenvolvimento de políticas públicas saudáveis. BIS - Boletim do Instituto de Saúde no 34 - Dezembro, 2004.

CAVAlCANTE, M. B. O papel da educação ambiental na era do desenvolvimento (in) sustentável. Revista Educação Ambiental em Ação [online]. Novo Hamburgo - RS, n. 36. 2011.

CHIARAVAlloti NETO, F.; MORAES M. S.; FERNANDES, M. A. Avaliação dos resultados de atividades de incentivo à participação da comunidade no controle da dengue em um bairro periférico do município de São José do Rio Preto, São Paulo, e da relação entre conhecimentos e práticas desta população. Cadernos de Saúde Pública, Rio de Janeiro, v. 14 (supl. 2); p. 101-109, 1998. 
COELHO, Giovanini Evekim. Dengue. Desafios atuais. Epidemiologia e Serviços de Saúde, Brasília, v. 17, n. 3, p. 231-233, Setembro 2008.

CROVELLO, T.J. \& HACKER, C.S. Evolutionary strategies in life table characteristics among feral and urban strains of Aedes aegypti (L.). Evolution v.26, p.185-96, 1972.

DIAS, João Carlos Pinto. Problemas e possibilidades de participação comunitária no controle das grandes endemias no Brasil. Cadernos de Saúde Pública, v. 14 (supl. 2), p. 19-37, 1998.

FREITAS, et al. Saúde e Comunidades Quilombolas: Uma Revisão da Literatura. Rev. CEFAC. 2011 Set-Out; 13(5):937-943.

PARE, M.L., OLIVEIRA, L. P., VELlOSO, A. D. A educação para quilombolas: experiências de São Miguel dos Pretos em Restinga Seca (RS) e da comunidade Kalunga do Engenho II (GO). Cad. Cedes, Campinas 2007;27(72):215-32.

LEBAZ, S., ZARHBOUCH, B., PICARD, D.. Conceptions naïves de la pollution chez les enfants de 7 à 12 ans : une étude de leurs dessins. Psychologie française, v. 65, p. 1-20, Jan. 2020.

LEMOS, Carolina Alves \& GUERRA, Teresinha. Aspectos dos Usos da água, agrotóxicos e percepção ambiental no meio rural, Maquiné, RS, Brasil. Revista on line Geografia - Volume 13 - Número 2jul/dez . 2004. Disponível em: http://www.uel.br/revistas/uel/index.php/geografia/article/view/6775 Porto Alegre - RS, 2004.

MI, L., QIAO, L., GAN, X., XU, T., LV, T., QIAO, Y., DING, C.. Assessing the effect of non-financial information intervention on promoting group-level energy savings. Science of the Total Environment, v. 720, Fev. 2020.

NEVES, V. L. F. C.; KATZ, G.; Utilização de ferramentas de análise espacial na vigilância epidemiológica de leishmaniose visceral americana - Araçatuba, São Paulo, Brasil, 1998 - 1999. Cad. Saúde Pública, Rio de Janeiro, 17(5), p. 1263-1267, set-out, 2001.

PASSOS, T.S.; HORA, A.B.; PAIXÃO, A. L. S. S. da; SANTOS, J.; ALMEIDA-SANTOS, M. A.; OLIVEIRA, C. C. C. Educação em saúde para prevenção de infecções sexualmente transmissíveis em comunidades quilombolas. Revista de Enfermagem, UFPE on line., Recife - PE, 11(10):3965-70, out., 2017. 3965.

PEREIRA, C. Etnobotânica na escola: Conhecimento etnobotânico e abordagem nas aulas de ciências. Trabalho de Conclusão de Curso - TCC. Instituto Federal de Educação, Ciência e Tecnologia de Santa Catarina -IFSC, Araranguá, SC, 2014, 27p.

PONCIANO, E. F.; SANTOS, A. C.; OLIVEIRA, R. N. C. A Educação Ambiental como estratégia de emancipação dos sujeitos: um estudo da Política de Saneamento Ambiental desenvolvida pela Funasa. Revista on line Caminhos de Geografia. Uberlândia - MG, v. 15, n. 49 Mar/2014 p. 175-181.

SALES, F. M. S. Ações de educação em saúde para prevenção e controle da dengue: um estudo em Icaraí, Caucaia, Ceará. Revista Ciência \& saúde coletiva, vol.13 no.1 Rio de Janeiro Jan./Feb. 2008. Disponível em: https://www.scielo.br/scielo.php?script=sci_arttext\&pid=S1413-81232008000100022 . Acesso em: 24.08.2020. 
SANTOS, A. C.; FIANCO, FIANCO, M. C.N.; CHAGAS, M. F. B.; SILVA, A. C. L.; CUNHA, C. R.; CARVALHO, E. M.; BATISTA, F. M. A.; Educação em saúde: Realização de oficinas de capacitação de combate ao Aedes aegypti e enfrentamento a microcefalia, dengue e outras arboviroses nos Correios, AGESPISA e ELETROBRÁS do Piauí/Brasil. In: II Congresso Internacional de Saúde Pública do Delta do Parnaíba 11/2016. Revista Interdisciplinar Ciências e Saúde - RICS. V. 3, n. 4 (2016). Anais do COPISP..., Parnaíba 2016. Disponível em: https://revistas.ufpi.br/index.php/rics/article/view/6342/3721. Acesso em: 17.08.2016.

SINTSPREVS/PI, Sindicato dos Trabalhadores Federais em Saúde e Previdência Social no Estado do Piauí. Notícias: Filiados ao Sintsprevs-PI promoveram ações de saúde em Comunidade Quilombola, no município de Oeiras. Portal Sintsprevs - PI. Notícia publicada em 01/02/2018 - 07:21, Teresina - PI. Disponível em: http://www.sintsprevs-pi.org.br/noticiasConteudo_inc.php?idNoticia=6110 . Acesso em: 26.08.2020.

SOUZA, W.V.; ALBUQUERQUE, M.F.P.M.; VAZQUEZ, E. et al. Microcephaly epidemic related to the Zika virus and living conditions in Recife, Northeast Brazil. BMC Public Health 18, 130 (2018). Disponível em: https://bmcpublichealth.biomedcentral.com/articles/10.1186/s12889-018-5039-z Acesso em: 09.10.2020.

TAVEIRA, L.A., FONTES, L.R., NATAL, D. Manual de diretrizes e procedimentos no controle do Aedes aegypti. Ribeirão Preto: Prefeitura Municipal de Ribeirão Preto, 2001. 